\title{
Ciencia útil en los ilustrados del Nuevo Reino de Granada (desde la llegada de Mutis hasta el Semanario del Nuevo Reyno de Granada)*
}

Recibido: 11/12/2018 | Revisado: 26/04/2019 | Aceptado: 09/05/2019 DOI: 10.17230/co-herencia.16.31.2

\author{
Gilberto Loaiza Cano** \\ gilberto.loaiza@correounivalle.edu.co
}

Resumen Este artículo pretende mostrar cómo hablar de
ciencia útil en la segunda mitad del siglo xviii,
en el Nuevo Reino de Granada, expresó un vín-
culo orgánico entre determinadas ciencias y las prioridades del
gobierno. La geografía, la botánica, la química, la medicina y,
especialmente, la historia natural, proveían información sobre
los recursos disponibles para la reorganización económica del
imperio español. Aquellos científicos criollos que se dedicaron
a las ciencias útiles terminaron siendo promotores de reformas
que presentaron ante el tribunal de la opinión pública, en una
forma de debate colectivo, como sucedió con el Semanario del
Nuevo Reyno de Granada.

Palabras clave:

Ilustración, ciencia, gobierno, expedición botánica, Estado.

\section{Useful science among the Ilustrados of the New Kingdom of Granada (from the arrival of Mutis to Semanario del Nuevo Reyno de Granada)}

Abstract This article aims to show how the reference to a useful science in the second half of the eighteenth century, in the New Kingdom of Granada, embraced an organic link between certain sciences and government priorities. Geography, botany, chemistry, medicine and, particularly, natural history, provided information on the resources available for
Este ensayo hace parte de otros dentro de una investigación aprobada por el Departamento de Filosofía de la Universidad del Valle, mediante presentación interna, titulada $\mathrm{El}$ momento ilustrado en la Nueva Granada, 1760-1808.

** Doctor en sociología del Instituto de Altos Estudios de América Latina (IHEAL), París III. Profesor del Departamento de Filosofía de la Universidad del Valle, Cali, Colombia. ORCID: 0000-00026161-7149. 
the economic reorganization of the Spanish empire. The creole scientists who devoted themselves to useful sciences ended up being promoters of reforms that they presented before the public opinion, as a way of collective debate, as in the case of Semanario del Nuevo Reyno de Granada.

\section{Keywords:}

Enlightment, science, government, royal botanical expedition, state.

Aquellos hombres que, en el Nuevo Reino de Granada, en la segunda mitad del siglo XVIII, participaron en la difusión de un nuevo espíritu científico dentro de las coordenadas de una Ilustración moderada ${ }^{1}$, limitada por la vigilancia del dogma católico, lograron no solamente persuadir sobre la utilidad de ciertas ciencias para la prosperidad del reino; sino también demostrar que reunían las capacidades para ejercer actividades de gobierno y que, por tanto, eran individuos disponibles para la ejecución de proyectos científicos que permitían a la Corona tener mejor control sobre la población y el territorio de sus posesiones en América. Proyectos científicos que, entre otras cosas, eran resultado de sus propias convicciones y experiencias, y que estaban sostenidos, en buena parte, en la iniciativa individual cuyo complemento ideal era el apoyo de las autoridades peninsulares.

Algunos estudiosos de esta época dirán que el hecho de haber sido activos difusores y oficiantes de ciertas formas de conocimiento los puso en un lugar privilegiado como agentes de expansión de los proyectos de dominación y reorganización administrativa del imperio. ${ }^{2}$ Esa es una interpretación cierta pero incompleta. Por supuesto, hacer ciencia (y ciencia útil para el imperio) era un hecho político incuestionable pero no dejaba de ser una práctica subordinada a los designios del poder. Los científicos criollos, intentaron persuadir a las autoridades españolas, principalmente, acerca de lo que era prioritario en el orden de reformas administrativas de la segunda mitad del siglo XVIII. La necesidad del mecenazgo de particulares, de la protección de autoridades de la Corona o de la aquiescencia directa del

1 Una caracterización de la Ilustración moderada española y de su prolongación en América puede encontrarse en Israel (2011).

2 Esta percepción de la Ilustración y su impacto en la actividad científica la han sabido sustentar las obras de Nieto Olarte (2007) y Castro Gómez (2010). 
rey soberano fue expresada en discursos, memorias e informes de estos oficiantes de las ciencias útiles para el reino.

Ahora bien, ser agentes de la razón ilustrada tenía que hallar complemento en las prácticas de aquellas formas de conocimiento que reunían determinadas virtudes porque estaban en sintonía con las prioridades organizativas de la economía política. Por alguna razón, la medicina, la botánica, la química y la geografía estaban en el primer renglón de los informes que aquellos científicos preparaban para las autoridades españolas. Eran ciertas formas de conocimiento las que correspondían con los procesos de racionalidad administrativa de un Estado. ${ }^{3}$

Es bueno advertir que esos científicos, que fueron forjando su capacidad y sus ambiciones para cumplir tareas de gobierno en el ejercicio de ciertas prácticas científicas (algunos de ellos por iniciativa personal o por vínculos con actividades colectivas como la Expedición Botánica), no pueden ser considerados como precursores de la revolución política que condujo a la separación de estos territorios de la dominación española. En la discusión historiográfica de los últimos años ha quedado derrotada la tradicional interpretación teleológica que les atribuía a personajes como Antonio Nariño, Francisco Antonio Zea o Francisco José de Caldas unas inclinaciones revolucionarias tempranas, que los habría convertido en subversores anticipados del orden monárquico. Como lo han dicho historiadores que han examinado los acontecimientos políticos de la segunda mitad del siglo XVIII, aquellos notables criollos eran leales a la Corona, pero estaban convencidos de la necesidad de algunas reformas administrativas, y habían hallado en los principios del derecho natural, de la economía política y de un republicanismo fundado en el bien común, la inspiración suficiente para sugerir la transformación de

3 En este ensayo no se piensa en el Estado-aparato según el tipo ideal weberiano; se comparte las precauciones que, por ejemplo, Carlos Garriga brinda para comprender cuál era la situación histórica del Estado en la segunda mitad del siglo XVIII y, al tiempo, se retoman las definiciones de lo que podía estar sucediendo con la estructura del Estado como aparato administrativo sugeridas por Michel Foucault en sus lecciones reunidas en Seguridad, territorio y población. Ni mucho optimismo para ver un Estado bien estructurado ni mucho escepticismo para no querer ver nada. Más bien un proceso de definición de prioridades en las acciones gubernamentales de la Corona española sobre sus posesiones americanas (Garriga, 2004). 
un imperio que, según ellos, requería reformas administrativas, luego de las recientes derrotas bélicas ante sus rivales europeos. ${ }^{4}$ Para ellos era importante que España recobrase su brillo y no tenían previsto en el horizonte inmediato un objetivo revolucionario que implicase trastornar el orden establecido.

¿Qué pretende entonces demostrar este ensayo? Que los ilustrados neogranadinos manifestaron su voluntad de gobierno, su deseo de participar en las prioridades gubernamentales de la Corona española mediante la difusión y práctica de lo que, en la segunda mitad del siglo XVIII, eran las ciencias útiles; que la politización de la ciencia o la ciencia enteramente al servicio del imperio fue un hecho notorio en que participaron consejeros y funcionarios de la Corona española y al que se unieron los criollos letrados en América. Esa politización fue creciente porque implicó, además de la demostración de la utilidad de determinadas ciencias, expandir un proyectismo sustentado en la reivindicación de la experiencia y de la observación directa como principio de autoridad. ${ }^{5}$ Por tanto, hablar de ciencias útiles era hablar de científicos útiles, es decir, de individuos capacitados para ejecutar las reformas que ellos mismos proponían.

En este ensayo no se ignoran las autorizadas contribuciones historiográficas en torno al activismo científico y político de los criollos ilustrados. Esas contribuciones debaten, por ejemplo, alrededor del grado de subordinación o autonomía de algunas actividades científicas y, en particular, de aquellas relacionadas con la Expedición Botánica. ${ }^{6}$ Puede ser cierto que José Celestino Mutis, y quienes lo acompañaron en aquella empresa científica, tuvieron un margen

4 Todo esto lo ha explicado con detalle Vanegas (2013). Sobre el republicanismo de Antiguo régimen, véase Thibaud (2017).

5 Por lo menos desde mediados del siglo XX, la historiografía sobre el mundo hispánico del siglo XVIII entendió que el proyectismo fue una especie de género de escritura en que viajeros, científicos, funcionarios civiles, militares y eclesiásticos escribieron proyectos, planes o propuestas de reforma que pretendían contribuir al bienestar de la Corona y sus dominios en América; de modo que entre historiadores de tal época el proyectismo señala la tendencia de algunos individuos letrados a intervenir con propuestas o planes de mejora de la acción gubernamental. En resumen, este feo sustantivo, al que puede añadírsele proyectista, no es raro entre historiadores ni en la documentación del siglo XVIII.

6 Esa discusión está presente en Amaya y Torres Moreno (2013). Allí los autores debaten con Nieto (2000). 
de libertad en sus acciones puesto que la Corona española no pudo controlarlas de modo absoluto; pero también parece cierto que esas acciones, con sus logros y fracasos inherentes, estuvieron sujetas a un momento de transformación estatal, que indicaba la prioridad de acudir a ciertas ciencias para mejorar la capacidad de administración económica de los recursos provenientes de las posesiones americanas. Eso quiere decir que las prácticas científicas y las valoraciones en torno a la importancia de ciertos conocimientos sobre otros, tuvieron inmediata relación con los propósitos ordenadores, centralizadores y racionalizadores del reformismo borbónico. Lo anterior se plasmó en una especie de dirigismo estatal en el que los criollos ilustrados fueron, o quisieron ser, unos agentes oficiosos.?

Pueden tener razón Amaya y Torres Moreno al mostrar, por ejemplo, que la Expedición Botánica escapó, en buena medida, de los controles fiscales de la Corona, y que eso puede ser prueba de la relativa autonomía intelectual de sus dirigentes científicos; pero eso no significa que sus acciones hayan quedado por fuera del marco de designios, tareas o prioridades del gobierno español en aquellos años. Es cierto también que muchos de los avances en el conocimiento del territorio y de la población obedecieron a iniciativas individuales o a propósitos pertinaces de figuras casi solitarias como Caldas. Puede ser que Mutis haya gozado de un "tratamiento de excepción" (Amaya y Torres Moreno, 2013, p. 54), o que Caldas hubiese caminado por las fragosidades del territorio apenas apoyado por algunos mecenas particulares o por sus convicciones; pero estas pretendidas excepcionalidades jamás se distanciaron de la preocupación común de la agenda gubernamental de la segunda mitad del siglo XVIII en las coordenadas del imperio español. Dicho de otro modo, sus comportamientos no fueron marginales ni mucho menos contestatarios y participaron, con los debidos matices, del propósito general de acumular conocimientos basados en la observación y la experiencia que permitiera suministrar información útil el buen gobierno. Ese ejercicio de acumular conocimiento sobre el espacio y la población neogranadinos sirvió para brindar algún grado de reconocimiento y de autoridad a

7 Eso nos aproxima a la caracterización que hace Renán Silva (2002, pp. 16-18), de esta pretendida "modernidad absolutista". 
unos individuos que habían hallado, en las ciencias útiles, un modo de conversar en una esfera pública coercitiva y jerárquica que, en el decenio de 1790, había aumentado las aprensiones sobre las actuaciones de los criollos letrados.

Esa politización creciente también tuvo expresión en algo, quizás menos evidente pero significativo en las relaciones de los súbditos con el poder: la escisión entre soberanía y gobierno, entre la incuestionable fidelidad al rey y el convencimiento de que, en asuntos de gobierno, era posible proponer reformas, enunciar tareas colectivas o participar como agentes estatales. Eso implicaba una separación entre la lealtad a la monarquía como dogma y la relativización del ejercicio cotidiano del poder, plasmado en acciones de gobierno. ${ }^{8} \mathrm{De}$ modo que, en nombre de la ciencia útil para la prosperidad del imperio, fue acentuándose una separación trascendental entre la obediencia al rey y la puesta en tela de juicio de las acciones de gobierno. Hubo en la cotidiana exaltación de la utilidad común de la ciencia un deslizamiento casi imperceptible pero significativo: en nombre de lo que era útil para el reino, algunos hombres provistos de las luces de la razón, comenzaron a sugerir reformas y a ponerlas en deliberación pública mediante los "papeles públicos".

Lo anterior entra en conversación con la obra sugestiva y potente del historiador francés Clément Thibaud quien, a propósito de los criollos neogranadinos, dice que luego de las conspiraciones de la década de 1790 hubo una "despolitización por la vía de la ciencia" (cette dépolitisation par la science), como si haberse dedicado a hacer ciencia hubiese significado asumir un papel muy distante de las preocupaciones por darle consistencia al orden monárquico, o por participar de tareas gubernamentales que aquellos mismos hombres juzgaron prioritarias (Thibaud, 2017, p. 214) ${ }^{10}$ Es más, este autor considera que entre 1794 y 1810 hubo un "periodo de latencia política en la esfera

8 Esta mutación trascendental dentro de la monarquía española es ampliamente examinada por Elías José Palti (2012; 2016).

9 "Papeles públicos": entre la segunda mitad del siglo XVIII y primeros decenios del siglo XIX es fácil hallar esta fórmula para referirse a los periódicos. La fórmula reveló, sobre todo en los decenios 1810 y 1820, en la América española, una relativa democratización de la palabra pública gracias a la multiplicación de talleres de imprenta que permitieron la aparición de periódicos.

10 Traducción libre al español de la versión original en francés. 
pública" ("une période de latence politique dans la sphere publique") (Thibaud, 2017, p. 217). ${ }^{11}$

En coincidencia con Thibaud, se considera en este ensayo que el Semanario del Nuevo Reyno de Granada testimonia una voluntad colectiva de proponer reformas en diversos planos de la acción gubernamental, y la capacidad y el deseo de ejecutarlas. Los criollos neogranadinos, especialmente aquellos que contribuyeron con sus opiniones sobre la naturaleza y la sociedad en el Correo Curioso de 1801 y en el Semanario, entre 1808 y 1811, hallaron en la discusión sobre las características del espacio natural local un modo de afirmarse epistemológica y políticamente, hasta el punto de construir un legado que bien pudo haber servido de punto de partida para reivindicar una élite esclarecida y capacitada para contribuir a "la felicidad de la sociedad civil", un propósito que pasaba por la exaltación "de las ricas potencialidades naturales del hemisferio" (Thibaud, 2017, p. 221). En ese sentido, se trataba de una élite comprometida con proyectar y realizar ciertas acciones en nombre de un Estado que, sobre todo desde la ruinosa guerra de los Siete Años, buscaba aplicar urgentes reformas en la relación de la Corona con sus posesiones americanas. En suma, una élite disponible para gobernar, pero insatisfecha por su condición subordinada.

Este ensayo hace parte de una investigación acerca del pensamiento político neogranadino durante el periodo ilustrado. Desde la segunda mitad del siglo XVIII hasta la crisis monárquica circularon ciertos postulados en el espacio público, a pesar de las restricciones censorias, y uno muy visible fue el sintagma de una "ciencia útil". Vamos a ver cómo la exaltación de la utilidad de la ciencia derivó en un proyectismo que expresaba, por un lado, una especie de distopía acerca de las carencias o ausencias de acción estatal; y, por otro, que aquellos individuos tenían la capacidad y la voluntad de gobernar; de modo que estos ilustrados hallaban nexo inmediato entre sus experiencias de adquisición de conocimiento sobre la naturaleza y la sociedad, con el deseo de emprender acciones como funcionarios de gobierno.

11 Traducción libre al español de la versión original en francés. 


\section{Ciencias útiles para el reino}

Puede atribuirse al médico José Celestino Mutis el establecimiento de unas ciencias útiles en el virreinato de la Nueva Granada en la segunda mitad del siglo XVIII. Al difundir nuevos paradigmas en la enseñanza de la medicina, la física y las matemáticas, acudió, con insistencia, a la exaltación de la utilidad de aquellas para el reino, para el público, para la gloria del monarca, para el lustre de las universidades y para las mismas ciencias entre sí. En su discurso de apertura del curso de matemáticas en el Colegio Mayor del Rosario, en Santafé de Bogotá, en 1762, dijo que "la utilidad de una ciencia parece ser el motivo que más obliga a cultivarla con algún empeño" (Mutis, 1983, p. 39). Un par de años más tarde habló, en su carta-representación dirigida a Carlos III con la intención de lograr apoyo para emprender una expedición botánica, de "la importancia de unos asuntos tan útiles al público como gloriosos al Monarca que los protege" (Mutis, 1968, p. 31).

Cuando Mutis hablaba de la utilidad de unas ciencias en particular se refería, por lo menos, a tres dimensiones: una en que lo conocido acerca de la naturaleza tuviese "útil aplicación en algún día para bien de los mortales". La observación y descripción de lo que provenía del conocimiento de la naturaleza debía quedar, además, depositado en "lugares públicos". Por tanto, un conocimiento difundido públicamente se volvía disponible para una "útil aplicación" en beneficio de la comunidad. La otra dimensión parecía inherente a la comunicación entre las mismas ciencias de modo que, por ejemplo, las matemáticas tenían utilidad para la física y la física le servía de apoyo a la enseñanza de la medicina. Y la tercera dimensión era aquella en que ciertas ciencias eran útiles porque servían para ejercer un buen gobierno, "para usar bien de lo conocido" (Mutis, 1968, p. 8). En esta última dimensión, por supuesto, unas ciencias tenían un lugar más relevante. En Mutis, como en otros, fue evidente el deseo de fomentar las ciencias naturales "en todos sus ramos" (Mutis, 1968, p. 31).

La asociación de la actividad científica con el ejercicio gubernamental quedó bien plasmada en la importancia creciente que Mutis y sus discípulos más directos les concedieron a las ciencias naturales 
con el fin de observar, describir y recolectar las "riquísimas producciones de toda la América española". En 1802, Francisco Antonio Zea lanzó una asertiva caracterización de lo que significaba la ya constituida Real Expedición Botánica. Desde París, Zea enviaba una definición del objeto de esta actividad científica:

El objeto de la Expedición de Historia Natural de Santafé es dar a conocer las riquezas naturales de aquel reino; mejorar las producciones útiles por medio del cultivo; propagarlas en el país haciendo conocer sus utilidades; sacar de ella todos los productos de que puedan aprovecharse la medicina, las artes y la economía; introducir en el comercio las que ofrezcan conocidas ventajas y contribuir el engrandecimiento del Real Gabinete, Jardín Botánico y Casa de Fieras de Madrid. Estos establecimientos han de atestiguar a la Europa el celo de la Expedición y ostentar el poder y la grandeza del Rey, acreditando la sabiduría de su gobierno y la ilustración de sus ministros. Deben ser los más ricos de la tierra, como lo es en el orden natural de la nación que los posee (Zea, 1985, pp. 88-89).

Estas convicciones tan rotundas acerca de concentrar los esfuerzos de la Corona, de los hombres de ciencia y, en general, de las gentes de letras en determinadas prácticas científicas que debían favorecer ciertas actividades económicas, merecen algún desentrañamiento. Testimonios como el de Zea y su maestro Mutis indican unos momentos históricos del Estado español y del desarrollo de la ciencia que, necesariamente, eran compatibles.

\section{Mutaciones del Estado}

España intentó, durante el reformismo borbón, poner en práctica los principios organizativos de un Estado que buscaba expandir la producción agrícola en sus posesiones coloniales y dinamizar la actividad mercantil a su favor. Para satisfacer esos propósitos, había ciencias que podían hacer una inmediata contribución a la renovada vocación estatal, es decir, que podían entrar en conexión inmediata con los objetivos de la economía política. Eso obligó a emprender tareas de conocimiento de la población y el territorio en América mediante expediciones científicas, censos e informes de burócratas. Para esto, era inminente acelerar la capacidad administrativa y 
cuantificadora del Estado mediante ingenieros, cartógrafos, médicos, botánicos. La necesidad de apropiación y utilización a gran escala de los recursos naturales sirvió de fundamento a técnicas e instrumentos de medición que fueron inventados o perfeccionados entre los siglos XVII y XVIII. La medición del orbe era el mejor antecedente que tenía España en el conocimiento riguroso de las distancias y formas de la Tierra, pues en 1736 partió hacia Perú una expedición francoespañola bajo la guía del astrónomo y matemático Louis Godin, a su lado viajaron los franceses Charles de La Condamine, Jussieu, Hugot, Morainville, Coplet y Pierre Bouguer; y los científicos españoles Jorge Juan y Antonio de Ulloa. Esta expedición, que duró casi una década, sentó las bases de observación y medición de América del Sur y fundamentó la curiosidad científica y los afanes gubernamentales de las décadas siguientes.

No es un dato despreciable que la carta-representación de Mutis enviada a su monarca haya sido escrita en 1764, cuando "Vuestra Majestad ha logrado ver el fruto de sus fatigas en la paz sólida que acaba de establecerse". Este se refería, sin duda, a la recién terminada guerra de los Siete Años (1756-1763) en la que se impusieron los británicos y España salió debilitada, pues en 1762 los primeros habían tomado La Habana y Manila. La derrota refrendaba el rezago del Estado español en los aspectos militar y administrativo; la obligación de España, si deseaba sobrevivir en la competencia con sus rivales europeos, era emprender rápidamente unas reformas que enderezaran su situación con respecto a estos y que le garantizara tener el control de sus posesiones en América. Mutis esperaba que, luego de la guerra, Madrid pudiese concentrarse, por fin, en tareas olvidadas o aplazadas; y era precisamente en el proyecto de hacer la Historia Natural de América que otros países, con sus viajeros y expediciones, habían tomado hace rato la delantera. En la competencia por expandir mercados y ampliar el campo de la ciencia, España estaba perdiendo.

Michel Foucault (2008), Immanuel Wallerstein (1998) y Anthony Pagden (1997) han explicado, cada uno a su modo, que durante el siglo XVIII las potencias europeas intentaron mutar la estructura de sus Estados para afrontar el desafío de controlar sus posesiones 
territoriales. La solución sugerida por muchos, desde inicios de aquel siglo, era "sustituir la conquista por el comercio" (Pagden, 1997, p. 152). Esta solución contó con autorizados voceros, entre ellos Montesquieu y Diderot, del lado francés; y Hume y Smith, del lado británico. Otros habían detenido su examen en la alicaída España, incluso de modo anticipatorio. La torpeza administrativa de España era evidente para pensadores más cercanos; por ejemplo, en 1741, el español José del Campillo y Cossío había sentenciado: "Enfermas están de muerte América y España; aquella porque esta no le da documentos; y esta, porque aquella no le tributa tesoros. Estos para la una, y aquellos para la otra, serán sus eficaces remedios" (Campillo y Cossío, 1789, p. 15). Poco después, en 1750, Pedro Rodríguez Campomanes, quien una década más tarde iba a ser el ministro de Hacienda de Carlos III, escribió un Bosquejo de política económica española, delineado sobre el estado presente de sus intereses. Allí insistía en el retraso administrativo español con sus colonias y en unas urgentes reformas. La aclimatación de las teorías de la economía política y de los fundamentos del libre comercio tuvieron su propio ritmo en España, en todo caso, para la segunda mitad del siglo XVIII, y especialmente después de la guerra de los Siete Años, esta intentó salir de su letargo en la administración de sus colonias y fraguó reformas en la composición y funcionamiento del Estado.

Si nos atenemos a lo sostenido por Wallerstein (1998), 1763 es un año decisivo en el cambio de las prioridades estatales españolas con respecto a sus colonias. Como bien lo ha explicado, la competencia comercial con Gran Bretaña tomó fuerza ese año; y España intentó combinar en su política económica y fiscal para América dos elementos en apariencia contradictorios: el libre comercio y el monopolio, esto es, una liberalización comercial sujeta a los designios de la metrópoli que permitiera ganar la partida a sus competidores británicos (Wallerstein, 1998, pp. 297-298). Desde entonces, puede verse el entronque de un Estado administrativo centralizador, con el despliegue institucional y discursivo de las ciencias útiles y con las novedades ideológicas de la Ilustración. Una relativa profesionalización de la burocracia estatal tenía su correlato en el afán de introducir cambios en los planes de estudio de las universidades y en 
la promoción de ciertas ciencias que correspondían con la apremiante necesidad de aprovechar los recursos naturales de las colonias en América.

Puede ser que España haya emprendido con tardanza la competencia económica entre Estados, lo cierto es que los postulados del mercantilismo comenzaron a cobrar sentido inmediatamente después de 1763. De ese modo, comenzaba a imponerse, en unas renovadas relaciones con sus colonias, el interés por expandir el conocimiento sobre los recursos que estas podían instalar en la órbita del comercio mundial. España fue entrando en la lógica de la competencia europea por el control de mercados pero, como lo dijo Michel Foucault, lo que estaba sucediendo entre las rivales potencias europeas tuvo incidencia en América (Foucault, 2004, p. 57). España y sus posesiones americanas entraban en esa nueva "racionalidad planetaria", las prioridades que fue definiendo España en la segunda mitad del siglo XVIII, y quizás con mayor decisión después del fin de la guerra de los Siete Años, tienen que ver con la irrupción del mercado como gran principio de acción administrativa del Estado. Explica el autor francés que fueron imponiéndose dos lemas centrales: la utilidad y el beneficio. La utilidad general, la de las cosas y los individuos; y el beneficio como resultado del intercambio. Ambos tuvieron inmediata relación con el ascenso, en el siglo XviII, de una nueva concepción de la economía cuyo fundamento fue el pensamiento fisiócrata que hablaba de la conjunción entre libertad de comercio y producción agrícola (Foucault, 2008, p. 53).

\section{"Tan útil para el Estado, como lo es para la ciencia"12}

La movilización de la razón gubernamental, si se apela de nuevo a las palabras de Michel Foucault, tuvo expresión, en España, en un pensamiento de la coyuntura que le pedía a la Corona racionalizar sus procedimientos en búsqueda de eficacia en muchos sentidos. Varios pensadores coincidieron en concentrar los esfuerzos en la agricultura y la población, "madres universales de la verdadera riqueza",

12 Son palabras de Francisco Antonio Zea en su plan para reorganizar las actividades de la Expedición Botánica, 1802; en: Hernández de Alba, G. (1985). 
para crear un "Nuevo Sistema de Gobierno Económico". Este afán de enriquecimiento, expresado en un cambio en la relación con sus posesiones en América, necesitaba como complemento un tipo de conocimiento que garantizase un vínculo ordenado y provechoso con los recursos naturales. No se trataba de animar la curiosidad sobre tierras exóticas, ni de contemplar paisajes exuberantes, sino de incursionar en sesta mediante la exploración, la medición, la compilación y la clasificación de especímenes, quizás, hubo algo de aquella convicción científica de la época que se plasmó en el deseo de "arrebatar a la naturaleza su secreto", algo que había comenzado a hacer Isaac Newton, ${ }^{13}$ quizás era hora de desvelar todos sus misterios, un propósito que condujo a la exaltación de la observación directa, a lo que se agregará, por el influjo de Buffon y después de Linneo, la pura descripción de cada elemento de la naturaleza, que parecía hallar pleno sentido en la historia natural y, en particular, en la botánica.

La botánica parece distinguirse por su capacidad (o necesidad) de acomodarse a su objeto de estudio y no de imponerle leyes o reglas. El botánico simplemente camina, observa y describe sus hallazgos que se van acumulando, y esa acumulación ya es un dato de variedad y riqueza, de generosidad de la naturaleza hacia el hombre. La utilidad de la botánica y de la geografía parecía estribar, en principio, en la capacidad de ambas ciencias de atesorar información sobre el mundo natural, de suministrar información acerca de los "misterios de la naturaleza". Cumplían con satisfacer la curiosidad, informaban sobre rarezas y riquezas porque permitían saber, con mucho detalle, qué se poseía. En la primera mitad del siglo XVIII hubo una especie de best-seller de aquel placer descriptivo del mundo natural, se llamó, con honesto sentido, Le Spectacle de la Nature (1732-1742). ${ }^{14}$ Pero en la segunda mitad del siglo aquella ensoñación había ido mutando; la naturaleza no era ya solamente un bello espectáculo, era un objeto de satisfacción de necesidades. No se trataba solamente de contem-

13 Ernst Cassirer dirá que el siglo XviII estuvo imbuido de la creencia de que había llegado el momento "de arrebatar a la naturaleza su secreto, tan cuidadosamente guardado, el momento en que ya no quedará en la oscuridad de siempre, en su calidad de misterio incomprensible" (Cassirer, 1994, p. 64).

14 Obra de Noel-Antoine Pluche publicada entre 1732 y 1742 en nueve volúmenes. Antes de que apareciese la Encyclopédie, esta obra se encargó de demostrar que la belleza de la naturaleza era obra de un dios sabio. 
plar la naturaleza cuya belleza ratificaba, por ejemplo, la existencia de Dios; la admiración de los elementos naturales tuvo que revestirse de racionalidad, e incluso cualquier intención puramente estética o mística de contemplación tenía que arrojar un dato sobre las propiedades de tal o cual elemento.

La botánica, quizás mucho más que la geografía, brindaba una doble utilidad. Por un lado, reivindicaba un dios creador que le entregaba al hombre un bello espectáculo de seres diversos; y, por otro, ponía a disposición del conocimiento de los gobernantes todo cuanto la naturaleza podía brindar para su provecho. Afirmación de lo divino y satisfacción de las necesidades mundanas provenían de esa forma de conocimiento o de esa forma de relación con el mundo natural. El científico, en este caso el botánico, podía sentirse sirviéndoles a su dios, a su monarca y a su ciencia.

La urgencia de vincular la agricultura y el comercio como actividades centrales de una nueva economía política orientada por la metrópoli encontró, en la botánica y en la geografía, unas formas de conocimiento que aseguraban esa necesidad de lo concreto que acompañaba este afán de lucro. La dominación de la naturaleza debía corresponder con la utilidad de lo concreto y, en consecuencia, con la inutilidad de lo abstracto, como lo había argumentado Condillac al exponer, hacia 1749, su Traité des systémes en que, entre otras cosas, les concedía enorme importancia a la observación científica y a los datos provenientes de la experiencia. ${ }^{15}$ Por eso, la observación directa, el viaje y la expedición científica con sus informes adquirieron relieve, pues estaban basados en la experiencia y en el contacto visual perfeccionado por los instrumentos.

Volcado el Estado español en las prioridades de la utilidad social, el provecho económico, la producción y comercialización a gran escala, les otorgó a ciertas formas de adquisición de conocimiento sobre la naturaleza un rango entre militar y empresarial. El lenguaje expedicionario, como ya otros lo han advertido, tiene su origen en la jerga militar, en las actividades de conquista; pero, esta vez, las expediciones eran dirigidas por organizaciones científicas que tenían la misión o encargo de dotar de información valiosa a un Estado

15 Para Condillac, "los principios abstractos son viciosos o, por lo menos, inútiles". A lo sumo, decía él, eran buenos "como máximas y proverbios que expresaban, de manera abreviada, lo que se ha logrado saber por experiencia” (Condillac, 1789, p. 166). 
que renovaba su burocracia y sus funciones administrativas en las colonias americanas.

Cuando Francisco Antonio Zea, uno de los discípulos más destacados del Mutis, escribió desde París su plan de reorganización de la Expedición Botánica del Nuevo Reino de Granada, después de casi veinte años de actividad (había iniciado en 1783), estaba plenamente convencido de que una actividad científica de tal índole debía estar destinada, primordialmente, a ser útil para la agricultura y el comercio. Así lo dijo al formular en su plan el objeto de la "expedición de Historia Natural de Santafé":

Dar a conocer las riquezas naturales del reino; mejorar las producciones útiles por medio del cultivo; propagarlas en el país haciendo conocer sus utilidades; sacar de ellas todos los productos de que puedan aprovecharse la medicina, las artes y la economía; introducir en el comercio las que ofrezcan conocidas ventajas [...] (Zea, 1985, pp. 88-89).

El proyecto reorganizativo de Zea contiene el sentido que, en su momento, podía otorgársele a una ciencia útil para el buen gobierno: la Expedición Botánica tenía que ser "tan útil al Estado, como lo es para la ciencia” (Zea, 1985, p. 90). El reglamento de funcionamiento que él proponía implicaba una estricta y jerarquizada división del trabajo, de tal manera que hubiese una autoridad científica, unas secciones especializadas, un personal capacitado para tareas muy precisas, la posibilidad de formar, por lo menos, una nueva generación de científicos en determinadas áreas. Eso explica, en parte, el extenso artículo dedicado a describir un ideal de distribución del trabajo. Algunas formas de hacer ciencia, en particular, exigían dotes intelectuales superiores o, al menos, una formación académica que garantizase el estrecho vínculo entre el conocimiento de la naturaleza y de la economía:

La botánica auxiliada de la química es la ciencia de que más necesita una nación favorecida de la naturaleza, para tener una agricultura floreciente y hacer un comercio ventajoso y en muchos ramos exclusivos. Por consiguiente un botánico que tenga nociones de química y sea naturalmente fecundo en ideas económicas, es para España un tesoro inestimable (Zea, 1985, p. 95). 
El plan de quien estaba por entonces bajo la tutela de AntoineLaurent de Jussieu, en París, era una afirmación del lugar que debía ocupar América del Sur en la economía mundial y que no era otro distinto que ser abastecedora de materias primas para la industrialización europea (Zea, 1985, p. 121). Cualquier expedición botánica, según ese designio, le adjudicaba una estricta utilidad a la historia natural en el conocimiento y promoción de cultivos de todas aquellas "producciones útiles que hayan descubierto"; por esto, preparar una agricultura destinada al comercio mundial le exigía a la empresa científica hacer conocer los cultivos, propagarlos, hacer experimentos y enseñar a manipularlos a los campesinos del virreinato. Este proyectismo científico y económico, cuyas consecuencias no examinaremos aquí, fue el sentido estratégico otorgado a aquella tarea científica cuya tarea más ardua consistía en hallar los productos agrícolas que sirvieran para el comercio trasatlántico de España.

\section{Ciencia para el gobierno: científicos y funcionarios}

Eran el Estado y sus redefiniciones en torno al buen gobierno los elementos que determinaron la condición de existencia de estas ciencias que debían cumplir funciones subsidiarias. La premisa parecía ser: "Primero lo útil y luego lo científico, es lo que se desea". Lo científico, en estricto sentido para algunos, podía y debía postergarse en aras de la utilidad. El mismo Zea lo advierte en su minucioso plan de funcionamiento de la Expedición Botánica: "lo científico" podía ser un extravío que distrajera los propósitos centrales de la vasta empresa. El director de la expedición debía, entonces, vigilar estas inclinaciones y dirigirlas hacia "lo útil" (Zea, 1985, p. 101).

Es evidente que las ciencias tenían que ser útiles para los gobernantes y amoldarse a los requerimientos del Estado; las actividades de los científicos expedicionarios estaban sujetas a las instrucciones de funcionarios de la monarquía y los informes de hallazgos y dificultades iban dirigidos a estos. Las ciencias eran útiles porque estaban sometidas a los designios de las prioridades económicas de la Corona. Algunos autores hablan de una tradición utilitaria en la constitución de las ciencias en la historia de España, y es muy probable que esa tradición haya adquirido fijeza en las actividades científicas 
de la segunda mitad del siglo XVIII, férreamente subordinadas a lo que era más indispensable en la competición económica global para España. ${ }^{16}$

No habrá que olvidar, para cualquier análisis de la conexión entre poder político y ejercicio científico, que la Expedición Botánica es casi coetánea del levantamiento comunero de 1781, de la resistencia pueblerina a las novedosas imposiciones fiscales y a un espíritu centralizador con fuerte halo autoritario. Basta leer las relaciones de mando de algunos virreyes para comprobar la importancia que adquirió en la agenda gubernamental de la época la creación de la Expedición Botánica bajo la dirección de Mutis. Por ejemplo, en uno de esos primeros informes virreinales se destacó que aquella labor científica no solamente estaba permitiendo enriquecer el gabinete de historia natural de Madrid, sino que principalmente estaba entregándole a la Corte noticias sobre el descubrimiento de "frutos y productos comerciables" (Caballero y Góngora, 1954, p. 111). Entre esos frutos había uno que captó particular interés para el rey, la quina. Las remisiones de todas las variedades encontradas de quina estuvieron mediadas por discusiones acerca de su calidad y las experimentaciones para garantizar los envíos estaban entre las tareas prioritarias de los expedicionarios. Las decisiones al respecto provenían del monarca, al virrey correspondía su aplicación, como cuando "autorizó Su Majestad al mismo Mutis para que nombrase quién le ayudase en los acopios con la inteligencia necesaria" (Caballero y Góngora, 1954, p. 112).

La correspondencia del propio director de la Expedición testimonia que prevalecía la interlocución con funcionarios de la Corona. Por supuesto, se entabló contacto ampliamente con algunos científicos, pero la comunicación obligatoria fue con los virreyes y secretarios del Estado español. Con ellos, la conversación tuvo un explícito lenguaje utilitario en que se hablaba de acopios de frutos y plantas útiles, del peso en arrobas y libras de los cajones que se enviaban a España y de las cuentas que podía hacer la Real Hacienda con esas remisiones. En todo caso, eran las indicaciones provenientes de la Corte las que determinaban las condiciones de cada envío. Mutis

16 A propósito de esta reflexión, ver De Vos (2007). 
tuvo que acostumbrarse a recibir instrucciones acerca de qué y cómo acopiar y cultivar, a qué frutos o plantas debía darles prelación, como queda bien evidenciado en una puntillosa carta de 1788 en que un secretario de Estado, siguiendo instrucciones del rey, le explicaba en detalle al cómo debía garantizar envíos de quina de "excelente calidad":

A fin de que no se confundan las especies de quina, y que aquí se compruebe fácilmente y sin confusión su más o menos ventajosa calidad para el destino que convenga darla, se tendrá especial cuidado en colocar con separación de cajones numerados cada clase, expresándose esta circunstancia y el paraje donde se ha cogido, en la respectiva rotulata (Porlier, 1968, pp. 185-186).

Quizás aún más ostensible fue la acción gubernamental alrededor de la mineralogía con la contratación del químico español Juan José D'Elhuyar y de siete mineros alemanes para adelantar la explotación de minas de plata. Para el virrey y arzobispo Caballero y Góngora fue importante determinar la rapidez de las extracciones diarias del metal y los dividendos que podía garantizar según la rapidez de los operarios (Caballero y Góngora, 1954, p. 119). Los hallazgos de botánica y mineralogía estuvieron, sin duda, bajo estricta supervisión de las autoridades de la Corona y los informes virreinales les dedicaron especial atención a los datos provenientes de estas actividades científicas que estaban estrictamente orientadas por la lógica de lucro del Estado español.

La subordinación de botánicos y químicos fue evidente, actuaron como funcionarios al servicio de la Corona y sus reportes de hallazgos contemplaban como prioridad la satisfacción de los deseos mercantiles de la época. Pero esta dimensión servil de algunas ciencias y sus oficiantes no fue la única existente; se sostiene en este ensayo que el ejercicio sistemático de actividades científicas útiles para la monarquía española también sirvió para formar un grupo de individuos que se sintieron capacitados para cumplir tareas de gobierno.

\section{La voluntad de gobierno}

La Expedición Botánica al mando de Mutis sirvió para formar una generación de criollos iniciados en las ciencias útiles demandadas por la Corona española; su formación no estuvo exenta de rivalida- 
des y celos, de competencia por la adquisición de prestigio y reconocimiento. Precisamente, tras el fallecimiento de Mutis, en septiembre de 1808, alentó una discusión acerca de quiénes debían ocupar su lugar o asumir algún liderazgo en las tareas científicas futuras. Francisco José de Caldas estuvo entre los primeros que cuestionó su obra y buscó, de inmediato, un lugar primordial en la precaria institucionalidad científica de entonces. En su memorial del 30 de septiembre de 1808, Caldas anunció que no iba a someterse a la dirección científica heredada por Sinforoso Mutis, el sobrino del cuestionado mentor: "Su tío le puso al frente de la Expedición, él sabría cómo. Yo quedo satisfecho con que se pongan mis colecciones de Quito bajo mi dirección, y que yo solo sea dueño de organizarlas" (De Caldas, 1966, pp. 353-354). Quizás más elocuente sea su reclamo por un reconocimiento individual de su obra científica y la afirmación de un derecho inalienable sobre los resultados de sus observaciones, porque el principal patrocinio para sus investigaciones había provenido de un protector particular, el comerciante cartagenero José Ignacio Pombo y, por tanto, no se sentía en deuda plena con el Rey ni con el fallecido Mutis. Declararse autor y dueño de su propia obra puede entenderse como un gesto de relativa autonomía:

Dos mil setecientos pesos fueron los únicos que me libró Mutis sobre las cajas de Quito en diferentes partidas, como consta de las cuentas de esta casa y de mi recibo. Si don José Ignacio Pombo, mi amigo y declarado protector, no me hubiera apoyado con más de tres mil pesos, jamás hubiera podido verificar tantos viajes, tantas colecciones y tantas observaciones. Tengo pues un derecho indisputable sobre mis trabajos, porque ellos se han ejecutado en la mayor parte a mis expensas (De Caldas, 1966, pp. 351-352).

El Semanario del Nuevo Reyno de Granada, fundado y dirigido por Caldas desde enero de 1808 hasta casi mediados de 1811, corresponde con este tono tan seguro de sí mismo. ${ }^{17}$ Pero esa seguridad no era

17 Vale la pena hacer una precisión sobre las fechas de circulación del Semanario. Es muy posible que la última Memoria (la n. ${ }^{\circ} 11$ ) sea posterior a marzo de 1811, según el "Elogio histórico" que hizo Caldas de Miguel Cabal, muerto en combate contra las tropas de Miguel Tacón y Rosique cerca de Popayán, el 28 de marzo de 1811. Lo que implica que el Semanario había quedado inevitablemente inmerso en las luchas políticas y militares que dieron origen a la llamada Primera República en la Nueva Granada. No es un dato 
un hecho aislado, en el periódico se reunieron aquellos jóvenes científicos y funcionarios criollos que sentían que, con lo poco o mucho que sabían, podían contribuir al buen gobierno. A su vez, creían y hacían creer que poseían unos conocimientos imprescindibles para ejercer la tutoría sobre su entorno social. Cuando Caldas asumió la dirección del periódico, ostentaba también la dirección del Observatorio Astronómico, un cargo que, según él, se le "entregó como un objeto secundario". Entre ambicioso y frustrado por no alcanzar el reconocimiento y prestigio que deseaba, Caldas asumió la dirección de un semanario que buscaba reafirmar la utilidad de ciertas formas de conocimiento.

El mismo Caldas inauguró el Semanario el 3 de enero de 1808, con una memoria sobre el "Estado de la Geografía del Virreynato" en el que integra una definición de la geografía económica, una reflexión de los alcances de esa ciencia en el gobierno del virreinato, y de cualquier unidad político-administrativa, una reflexión sobre su propia condición de criollo, un balance de la situación del conocimiento del territorio y la población, que derivó en un esbozo de plan para culminar la tarea científica de conocer los recursos naturales y las características físicas y morales de la población. Su pretensión era integral y aparece insinuada desde el epígrafe; en efecto, el fundador y director del Semanario del Nuevo Reyno acude a las palabras del comerciante vasco Nicolás Arriquibar, fundador de la Sociedad Bascongada de Amigos del País y, como solía decirse en el siglo XVIII, un conocido proyectista que abogaba por dotar de las precisiones de la aritmética el ejercicio del gobierno. La frase escogida como epígrafe decía: "La Geografía es la base de toda especulación política". ${ }^{18}$ Caldas, como otros criollos ilustrados neogranadinos, estaba con-

deleznable que Caldas llegó a ser responsable, al mismo tiempo, de dos periódicos: el Semanario y el Diario político de Santafé de Bogotá, que comenzó a circular el 27 de agosto de 1810.

18 Otros historiadores le han dado alguna importancia, pero no la suficiente, al epígrafe de su memoria, basado en la obra de alguien que había sido miembro de la Real Sociedad Bascongada de Amigos del País y, más interesante aún, difusor en España de los métodos estadísticos aplicados a la administración estatal. Al respecto, ver Nieto (2007, p. 108). El libro de Arriquibar que debió leer Caldas es una mixtura; en la primera parte, el comerciante vasco tradujo de Charles Davenant un opúsculo titulado "Del uso de la aritmética en el comercio y rentas", que data de 1698. Luego vienen las reflexiones de Arriquibar conocidas como "Recreación política" y que dan título a todo el libro. 
vencido de la importancia de las matemáticas aplicadas al funcionamiento del Estado. Pero la evocación de la obra de alguien del otro lado del Atlántico, que también estaba interesado en la aplicación de las matemáticas al cálculo económico y a la organización política, permite pensar que muchos, entre el selecto mundo letrado de entonces, compartían el deseo de ver un Estado dotado de las herramientas seguras y precisas de la medición, el cálculo y el pronóstico.

El pensamiento geográfico de quien ostentaba la dirección del Observatorio Astronómico de Santafé de Bogotá estaba influenciado por postulados que afirmaban la preeminencia de la "aritmética política”, como la ciencia que permitía dotar de cálculos y exactitud a la actividad cotidiana del Estado. La frase que Caldas tomó del vasco Arriquibar proviene de una reflexión aplicada a la península sobre el avance español en la elaboración de mapas de sus dominios. El recurso científico de la geografía servía, según la reflexión de Arriquibar, al "perfecto conocimiento de nuestras tierras" para "los establecimientos de industria, comercio, navegación y agricultura" (Arriquibar, 1779, p. 90). ${ }^{19}$

La memoria de Caldas ocupó los seis primeros números del periódico y es una larga reivindicación del conocimiento geográfico como fundamento "de toda especulación política". En las primeras líneas definió el objeto de estudio de la geografía económica, una manera de adjudicarle preeminencia en el orden de los saberes indispensables para el ejercicio de un buen gobierno:

Ella da la extensión del país sobre que se quiere obrar, enseña las relaciones que tiene con los demás pueblos de la tierra, la bondad de sus costas, los ríos navegables, las montañas que le atraviesan, los valles que forman, las distancias recíprocas de las poblaciones, los caminos establecidos, los que se pueden establecer, el clima, la temperatura, la elevación sobre el mar de todos los puntos, el genio, las costumbres de sus habitantes, sus producciones espontáneas, y las que puede domiciliar con el arte (De Caldas, 1808a, p. 1).

La vastedad de esta definición no puede entenderse como la simple exaltación de una forma de saber, pues al leer el detallado informe,

19 En el mismo párrafo de la frase que adoptó Caldas como epígrafe, Arriquibar lamentaba que desde mucho tiempo España no conocía "planes o mapas de nuestras propias tierras" (Arriquibar, 1779, pp. 89-90) 
parece claro que Caldas ha querido demostrar, además, que él era, hasta entonces, el único capaz de cumplir o aproximarse a la plena satisfacción de un programa científico de tal envergadura. Conocer, medir, cuantificar el país era, casi quedaba dicho por Caldas, poseerlo o, al menos, estar en disposición insuperable para ejercer alguna tutela sobre la definición de una agenda gubernamental. La memoria es una exhibición de autoridad científica adquirida por la experiencia de la observación directa, por las mediciones y correcciones de datos que otros habían construido con alguna inexactitud.

No es posible detenerse aquí en la muy discutida tesis acerca del influjo del clima en la condición moral de la sociedad, pero se puede destacar que la memoria geográfica de Caldas sirvió para ubicar en cada lugar, según su criterio, las cosas y los hombres. Situar el espacio neogranadino en las coordenadas del orden económico global, otorgarle a cada accidente geográfico un probable destino, situar las jerarquías humanas según su relación con cada espacio. Además de exhibir su autoridad científica para cumplir esa tarea omnisciente, Caldas se otorgó un lugar preeminente en el orden social:

Entiendo por Europeos no solo los que han nacido en esa parte de la tierra, sino también sus hijos, que conservando la pureza de su origen jamás se han mezclado con las demás castas. A estos se conoce en la América con el nombre de Criollos, y constituyen la nobleza del nuevo Continente quando [sic] sus padres la han tenido en su país natal (De Caldas, 1808a, p. 11).

Más reveladora es la especie de programa, entre político y científico, con que remató su memoria. La hibridez de su reflexión final, donde la ambición científica se confunde con el ánimo de incidir en el ejercicio político, muestra la doble situación de hacer o querer hacer ciencia en aquel momento. Hacer ciencia para ordenar, para prosperar, para administrar, para conocer y poseer. Caldas, en su balance, hizo evidente que la tarea científica de observar y medir todo el territorio estaba incompleta y urgía conseguir recursos para iniciar viajes de expedición "para el escrupuloso reconocimiento de las provincias". Además, es revelador que enumerase aquellos oficios o funciones que tenían estrecha relación con todas las posibles formas técnicas de administración gubernamental. Las ciencias y, en este 
caso, la geografía, pertenecen a la mundanidad de la racionalidad estatal, donde se diseñan las fórmulas de control del territorio y de la población; quizás por eso Caldas invocaba a todos aquellos que debían estar involucrados en las tareas de gobierno con los hallazgos de las expediciones científicas:

Aquí vendrán el Político, el Magistrado, el Filósofo, el Negociante a beber luces para el desempeño de sus oficios; aquí el Viajero, el Botánico, el Mineralogista, el que se ocupa con los seres vivientes, el Militar y el Agricultor verán con rasgos majestuosos pintados sus intereses. Todas las clases del estado vendrán a tomar aquí la parte que les toca (De Caldas, 1808a, p. 45).

Es muy posible que Caldas estuviese participando de alguna definición del Estado, representado en estos ejecutantes de su voluntad o de las acciones que lo beneficiarían. Se puede inferir, además, que estaba dando una definición, por extensión, de lo que podía entenderse, en aquel entonces, por Estado, pues haciendo la enumeración de "todas las clases del estado" estaba diciendo quiénes lo componían (es muy diciente que no aparezcan ni el rey ni el sacerdote católico, por ejemplo)..$^{20}$ En las actividades de gobierno, en el conocimiento de los recursos naturales, del territorio y de la población intervenían todas estas convenciones mundanas, técnicas y racionales condensadas en cierto tipo de funcionarios. Probablemente de esta forma esté revelando también que era partícipe, consciente o inconsciente, de la escisión entre soberanía y gobierno. De un lado, el rey con su aura sagrada y detentador absoluto de soberanía; de otro, los funcionarios, ejecutantes de las acciones gubernamentales, piezas de la maquinaria estatal. El primero puesto en la esfera de lo infalible y lo incuestionable; los otros situados en lo terrenal, falible y perfectible. ${ }^{21}$

Una incipiente comunidad científica que buscaba un lugar en las actividades racionalizadoras del Estado es lo que alcanza a legarnos el Semanario del Nuevo Reyno de Granada. Lo que postulaba o deseaba Caldas tuvo concreción en números posteriores con las colaboraciones de funcionarios de provincia, muchas de estas memorias

20 Aunque varios sacerdotes católicos incursionaron en las páginas del Semanario, Caldas tuvo una fuerte controversia con el cura Eloy Valenzuela por el pago de una suscripción al periódico (De Caldas, 1808b).

21 Ver Palti (2016). 
descriptivas que contribuían al deseado mapa general del virreinato. Entre todas esas contribuciones interesa detenerse en una que testimonia la aplicación del conocimiento geográfico a una explícita intención de gobernar. Se trata del "Discurso" de Frutos Joaquín Gutiérrez, "abogado de la Real Audiencia, Catedrático de Derecho Canónico", ${ }^{22}$ dedicado a proponer la erección de obispados en el virreinato. Su proyecto reformador de la presencia de la Iglesia católica en el virreinato estaba sustentado en la premisa institucional del regalismo que le confería al Estado español la potestad de regir la actividad eclesiástica en una demostración de hacer prevalecer el bien común, incluso por encima de esta. El regalismo era pues un ejercicio de soberanía estatal y, además, prueba del triunfo de la política sobre la religión. Era el rey quien ostentaba la potestad para intervenir en todo lo concerniente a la presencia institucional de la Iglesia católica en sus dominios. ${ }^{23}$ En este caso, un intelectual criollo formado en derecho canónico se sintió con la autoridad suficiente para presentarle al monarca, en nombre de la ley y "la común utilidad", una propuesta de erección de "Sillas Episcopales en muchos pueblos del Reyno" (Gutiérrez, 1808, No. 42, p. 364). Lo más interesante del "Discurso" del abogado criollo Frutos Joaquín Gutiérrez es que parte "del conocimiento de nosotros mismos" (Gutiérrez, 1808, No. 48, p. 412) para que el monarca español proceda con autoridad en la división y erección de obispados en el territorio americano. "Concibamos las empresas y demos impulso a los proyectos con todo el valor que debe inspirarnos la beneficencia de un Monarca que quiere y puede hacernos felices" (Gutiérrez, 1808, No. 48, p. 413), de ese modo, el autor del proyecto de una nueva distribución del personal eclesiástico en el virreinato revelaba el lugar que ocupaba en el proceso de reformas administrativas de la época. Sus conocimientos del derecho canónico y de la geografía local lo facultaban para proponerle a la Corona una reforma en el complejo asunto de las relaciones de la monarquía con la Iglesia católica.

22 Frutos Joaquín Gutiérrez, "Discurso", Semanario del Nuevo Reyno de Granada, No. 42, Santafé, 16 de octubre de 1808, p. 362. El "Discurso" de Gutiérrez se extendió hasta el No. 53.

23 Una prolija descripción del regalismo español en el siglo XVIII se puede encontrar en Pacheco (1986). 
En el discurso de Gutiérrez, la política eclesiástica en América debía tener en cuenta "lo vasto y dilatado de sus territorios [...] la fragosidad de sus caminos [...] la multiplicación de sus habitantes", (Gutiérrez, 1808, No. 48, p. 413) entre otros factores. Con esto como premisa, podía decidirse acerca de dónde y por qué debían erigirse obispados. Su plan administrativo que implicaba la preeminencia del Estado sobre la Iglesia católica fue sustentado, en varios números del semanario, en los conocimientos geográficos acumulados hasta entonces. Gutiérrez fue prolijo en la caracterización del territorio para sugerir demarcaciones administrativas, según regiones que compartían rasgos espaciales y poblacionales. Su propuesta iba constituyendo un mapa de las jerarquías eclesiásticas distribuidas por el virreinato, siempre pensando en el bien común. Aquí se hace evidente la conversación con la memoria inaugural de Caldas y las de otros colaboradores en el periódico. Con todos ellos compartió el determinismo geográfico en la caracterización de las costumbres y valores de cada grupo poblacional. Su propuesta de división administrativa de la Iglesia católica emanó de su condición de miembro de un poder civil y se sustentó en la intención de poner en cierta sintonía lo civil con lo eclesiástico, teniendo en cuenta la información proveniente de las descripciones proporcionadas por viajeros y geógrafos.

El "Discurso" de Gutiérrez ha pasado casi inadvertido en los análisis contemporáneos de la obra colectiva condensada en aquel periódico, sin embargo, plasma la voluntad de gobierno de un grupo de individuos que sentían que habían adquirido los conocimientos, la notoriedad y la posición suficientes para ser agentes de gobierno, dispuestos a cumplir funciones administrativas en nombre del Estado, en un proceso racionalizador que ellos mismos estaban contribuyendo a cimentar.

\section{Conclusiones sobre un discurso utilitario}

Desde Mutis hasta el Semanario dirigido por Caldas hubo una difusión notoria de un discurso sobre la utilidad que no era exclusivo del ámbito de las ciencias de aquella época. La utilidad común era parte de los principios organizativos de la sociedad, acerca de eso testimonian con amplitud varios periódicos que existieron en 
el lapso de tiempo que hemos examinado. El Papel Periódico de Santafé (1791-1797) inició su circulación con el lema condensado en un epígrafe que decía: "La común utilidad es el vínculo más estrecho de la sociedad" (Communis utilitas societatis máximum est vinculum). Más insistente con este discurso fue el Correo Curioso (1801) pues para sus redactores el lenguaje utilitario era primordial entre buenos ciudadanos, obedientes a la religión católica, al monarca y a las leyes, es decir, consideraba que la armonía social estaba basada en la obediencia a un orden político de origen divino, principio rector del absolutismo, y obtenía su firmeza en la preocupación por el bien común y por la prosperidad del reino. Había que tener pues una disposición permanente para proponer todo aquello que fuese útil para conservar la armonía social y fomentar el beneficio de todos los súbditos del rey. Esta determinación utilitaria, por lo menos hasta inicios de la década de 1800 , estaba sustentada en una sociabilidad que establecía un

mutuo enlace de trato, vida, comunicación, auxilios, alimentos, placeres, trabajos, ideas, pensamientos, ilustración; a un mismo tiempo entre las jerarquías de los superiores, e inferiores; de los nobles, y los plebeyos; de los buenos, y los malos; de los sabios, y los ignorantes. ${ }^{24}$

Esta vida relacional jerárquica, inmutable y de mutua dependencia entre los individuos obligaba a hablar, al menos en los papeles públicos de esos años, en nombre de la felicidad común, y cualquier viso de iniciativa individual apuntaba hacia el egoísmo como disonancia o desobediencia que ponía en riesgo la conservación del orden. Sin embargo, la publicación de las opiniones individuales, basadas en la experiencia y en la observación, le permitió a un grupo de individuos sugerir reformas que partían del supuesto de que la actividad gubernamental era tan falible como el mismo conocimiento científico y que era menester corregir o empezar a hacer aquello que no se había hecho. Eso es lo que puede entreverse en los tres años y poco más de existencia del Semanario del Nuevo Reyno de Granada. El punto de

24 "Continúa la exhortación de la patria", Correo curioso, erudito, económico y mercantil, Santafé de Bogotá, No. 3, 3 de marzo de 1801, p. 2. Sin embargo, el periódico intentó privilegiar el artículo científico sobre otros temas. 
partida de muchos discursos, memorias e informes fue la perfectibilidad del modo de gobierno, el cuestionamiento de lo existente y la posibilidad de participar en la ejecución de reformas administrativas del Estado. ${ }^{25}$ Es muy posible que todo esto significase una mutación de lo que podía entenderse por Estado o administración pública, en todo caso, quienes estuvieron reunidos en torno al Semanario emergieron como individuos capacitados para cumplir tareas de gobierno.

Es cierto que otros historiadores han hecho un excelente examen de la relación entre ciencia y política y, como lo dijo Mauricio Nieto, la historia de la ciencia puede entenderse como historia política. Sin embargo, definir el asunto de ese modo no parece suficiente. Ha sido más interesante pensar, para el caso de este ensayo, que hacer ciencia útil para el bien de los propósitos de la Corona terminó favoreciendo, de un modo quizás no previsto, la iniciativa individual y la consolidación de una autonomía que permitiera poner en deliberación, ante el tribunal de la opinión, propuestas de gobierno cimentadas en el conocimiento científico. Precisamente esa deliberación pública acerca de las prioridades gubernamentales partía de la insatisfacción y la puesta en tela de juicio de lo que había en ese entonces. De tal modo que el discurso de la ciencia útil que parecía cumplir una función orgánica en el sostenimiento del orden monárquico terminaba siendo, en su uso cotidiano y público, una manifestación de la incompatibilidad entre lo existente y lo que estos hombres de ciencia consideraban como tareas gubernamentales apremiantes.

Es cierto que en el momento histórico examinado en este ensayo se asiste a una glorificación de la ciencia como un instrumento indicativo de superioridad de una élite. Hacer ciencia y, sobre todo, hacer ciencia útil para los afanes de la monarquía establecía un tipo de vínculo entre el poder político y el ejercicio de ciertas formas de conocimiento. ${ }^{26}$ Pero esto no volvió al científico (y su ciencia) un individuo del todo imprescindible ni superior, su subordinación

25 El Semanario dirigido por Caldas podría señalar una ruptura comunicativa respecto a otros periódicos que le precedieron en el virreinato de la Nueva Granada. En el modo de exposición de los discursos, memorias e informes hay una disposición a la deliberación pública y a someter cada experiencia o hallazgo al tribunal de la opinión. Esto merece examen más detallado en otro ensayo.

26 En este ensayo se comparten las apreciaciones de Castro Gómez (2010, pp. 187-193). 
fue evidente pues el conocimiento científico tenía que satisfacer las necesidades imperiales y, en medio de esa condición subordinada, el criollo letrado creyó que encontraba un lugar privilegiado o, al menos, decisivo en la actividad gubernamental al nivel local.

La ciencia útil y las prácticas mercantiles se volvieron temas recurrentes en los escritos de funcionarios que palpaban la decadencia económica de España, y ese lenguaje de la utilidad tuvo resonancia en las prácticas científicas en las posesiones americanas. Y, quizás, de un modo muy limitado y marginal, ese personal criollo letrado estaba queriendo participar de un proceso más vasto de "racionalidad planetaria" (Foucault, 2004, p. 58) en que el Estado debía convertirse en una máquina de racionalidad, precisión, cuantificación y orden para ejercer el control de territorios y población. Pero eso fue más deseo que realización.

Además, el recurso de la ciencia para garantizar acción política debió ser insuficiente y puede, en parte, ayudar a entender por qué el mismo Francisco José de Caldas experimentó de modo simultáneo dos modos de escritura pública, la que intentaba sostener el carácter científico del Semanario desde 1808, y la que daba cuenta de la coyuntura decisiva en el momento de la vacatio regis en el Diario Político de Santafé de Bogotá, desde 1810. Haberse vuelto responsable, de forma simultánea, de esos dos periódicos indica, a la vez, una contigüidad y una diferenciación entre lo que debía ser ciencia útil para el buen gobierno y lo que debía ser la posibilidad de gobernar en medio de la crisis monárquica 


\section{Referencias}

Amaya, J. A. y Torres Moreno, J. V. (2013). La Expedición Botánica a la luz de las cifras, 1783-1816. En O. Restrepo (ed.), Ensamblando estados (Tomo 1) (pp. 41-75). Bogotá: Universidad Nacional de Colombia.

Arriquibar, N. (1779). Recreación política. Reflexiones sobre el amigo de los hombres en su tratado de población, considerado con respecto a nuestros intereses. Vergara: Imprenta de la Real Sociedad Bascongada.

Caballero y Góngora, A. (1954). Relación del estado del Nuevo Reino de Granada que hace el arzobispo de Córdoba, Antonio Caballero y Góngora, a su sucesor, 1789. En G. Giraldo Jaramillo (comp.), Relaciones de mando de los virreyes de la Nueva Granada (pp. 98-143). Bogotá: Banco de la República.

Castro Gómez, S. (2010). La Hybris del Punto Cero. Ciencia, raza e ilustración en la Nueva Granada (1750-1816). Bogotá: Editorial Pontificia Universidad Javeriana.

Cassirer, E. (1994). Filosofía de la Ilustración. México: Fondo de Cultura Económica.

De Caldas, F.J. Obras Completas de Francisco José de Caldas. Bogotá: Universidad Nacional de Colombia, 1966.

De Caldas, F. J. (3 de enero de 1808a). Estado de la Geografía del Virreynato de Santafé de Bogotá. Semanario del Nuevo Reyno de Granada, 1.

De Caldas, F. J. (7 de febrero de 1808b). Continuación de Estado de la Geografía del Virreynato de Santafé de Bogotá. Semanario del Nuevo Reyno de Granada, 6.

De Condillac, E. B. (1798). Traité des systemes. Paris: Ch. Houel Imprimeur.

De Vos, P. (2007). Natural History and the Pursuit of Empire in Eighteenth-Century Spain. Eighteenth-Century Studies, 40(2), 209-239.

Del Campillo y Cossío, J. (1789). Nuevo sistema de gobierno económico para la América. Madrid: Imprenta de Benito Cano.

Foucault, M. (2004). Naissance de la biopolitique. Cours au Collège de France, 1978-1979. Paris: Seuil-Gallimard.

Foucault, M. (2008). Seguridad, territorio, población. Curso del Collège de France, 1977-1978. Madrid: Ediciones Akal.

Garriga, C. (2004). Orden jurídico y poder político en el Antiguo Régimen. Revista Istor, 4(16), 3-44.

Israel, J. (2011). Democratic Enlightenment. Philosophy, Révolution and Human Rights, 17501850. New York: Oxford University Press.

Mutis, J. C. (1968). Representación hecha a su Majestad Carlos III, Santafé, 26 de junio de 1764. En G. Hernández de Alba (comp.), Archivo epistolar (Tomo 1) (pp. 31-43). Bogotá: Ediciones Kelly. 
Mutis, J. C. (1983). Discurso preliminar pronunciado en la apertura del Curso de Matemáticas, el día 13 de marzo de 1762, en el Colegio Mayor del Rosario de Santafé de Bogotá. En G. Hernández de Alba (comp.), Escritos científicos de don José Celestino Mutis (pp. 3947). Bogotá: Ediciones Kelly.

Nieto Olarte, M. (2000). Remedios para el imperio: historia natural y la apropiación del Nuevo Mundo. Bogotá: Instituto Colombiano de Antropología e Historia.

Nieto Olarte, M. (2007). Orden natural y orden social. Ciencia y política en el Semanario del Nuevo Reyno de Granada. Bogotá: Universidad de los Andes.

Ortega, F. A. y Chicangana, Y. A. (eds.), (2012). Conceptos fundamentales de la cultura política de la Independencia. Bogotá: Universidad Nacional de Colombia.

Pacheco, J. M. (1986). Historia eclesiástica. La Iglesia bajo el regalismo de los borbones. Siglo XVIII. En Historia extensa de Colombia (Tomo 4), XIII. Bogotá: Academia Colombiana de Historia, 1986.

Pagden, A. (1997). Señores de todo el mundo. Ideologías del imperio en España. Inglaterra y Francia (siglos XVI, XVII y XVIII). Barcelona: Ediciones Península.

Palti, E. J. (2012). Joaquín de Finestrad y el problema de los orígenes ideológicos de la revolución. En F. A. Ortega y Y. A. Chicangana (eds.), Conceptos fundamentales de la cultura política de la Independencia. Bogotá: Universidad Nacional de Colombia.

Palti, E. J. (2016). An Archaeology of the Political. Regimes of Power from the Seventeenth Century to the Present. New York: Columbia University Press.

Pluche, N. A. (1739). Le Spectacle de la Nature. París: Veuve Estienne.

Porlier, Antonio. (1968). Carta de Antonio Porlier, secretario de Estado español a José Celestino Mutis, Aranjuez, 12 de mayo de 1788. En: G. Hernández de Alba (comp.), Archivo epistolar (Tomo IV) (pp. 185-186). Bogotá: Editorial Kelly.

Rodríguez de Campomanes, Pedro. (1984). Bosquejo de política económica española, delineado sobre el estado presente de sus intereses. Madrid: Editora Nacional.

Silva, R. (2002). Los Ilustrados de Nueva Granada, 1760-1808. Genealogía de una comunidad de interpretación. Medellín: Banco de la República/EAFIT.

Thibaud, C. (2017). Libérer le Nouveau Monde. La fondation des premieres républiques hispaniques. Colombie et Venezuela (1780-1820). Rennes: Éditions Les Perseides.

Vanegas, I. (2013). La Revolución neogranadina. Bogotá: Ediciones Plural.

Wallerstein, I. (1998). El moderno sistema mundial (Tomo III). Madrid: Siglo XXI Editores.

Zea, F. A. (1985). Luminoso Plan Reorgánico de la Real Expedición Botánica propuesto desde la ciudad de París por don Francisco Antonio Zea. En G. Hernández de Alba (comp.), Documentos para la Historia de la educación en Colombia,1800-1805 (Tomo VI) (pp. 88-132). Bogotá: Editorial Kelly. 